\title{
USO E SEGURANÇA DO MÉTODO OCLUSÃO VASCULAR
}

Para o uso adequado do método, é muito importante entender sobre a sua aplicação, quais áreas mais utilizam o método, quais são as finalidades envolvidas com seu uso, idade que pode ser aplicado e principalmente os seus principais efeitos adversos.

Em 2006, no Japão, foi realizada uma pesquisa para saber, quais finalidades o método oclusão vascular foi utilizado e possíveis efeitos adversos (NAKAJIMA et al., 2006). Cerca de 105 instalaçóes participaram do estudo. De acordo com a Quadro 1, adaptado de Nakajima et al. (2006), podemos verificar os tipos de instalações que participaram do estudo.

Quadro 1 Tipos de instalações

\begin{tabular}{|cc|}
\hline Tipos de instalações & Frequência e percentual \\
\hline Outros & $15(14 \%)$ \\
\hline Academias & $28(27 \%)$ \\
\hline Hospitais e clínicas & $23(22 \%)$ \\
\hline Escritórios de osteopatia & $25(24 \%)$ \\
\hline Centros de reabilitação & $23(22 \%)$ \\
\hline Escritórios de acupuntura & $11(10 \%)$ \\
\hline
\end{tabular}


Além disso, o método tem sido utilizado nas áreas de esportes, atividade físi$\mathrm{ca}$, tratamento de doenças cardiovasculares, tratamento de doenças cerebrovasculares, tratamento de doenças neuromusculares, tratamento doenças ortopédicas, tratamento do diabetes mellitus, tratamento da obesidade, tratamento de doenças renais, tratamento da hipertensão, tratamento de depressão, prevenção de atrofia, aumento da força muscular e doenças respiratórias.

Em relação a idade, o Quadro 2, adaptado de Nakakima et al. (2006), apresenta as idades dos indivíduos que receberam o método nas 105 instalações. Com isso, percebe-se que o treinamento pode ser aplicado de forma ampla e sem restrições em relação a idade.

Quadro 2 Idade das pessoas

\begin{tabular}{|cc|}
\hline Idade & Percentual \\
\hline 70 anos & $10,2 \%$ \\
\hline$\geq 80$ anos & $4,4 \%$ \\
\hline$\leq 19$ anos & $17,8 \%$ \\
\hline 20 anos & $12,4 \%$ \\
\hline 30 anos & $12,7 \%$ \\
\hline 40 anos & $13,1 \%$ \\
\hline 50 anos & $15,5 \%$ \\
\hline 60 anos & $14,0 \%$ \\
\hline
\end{tabular}

Apesar dos benefícios do método, quando a pressão é aplicada de forma inadequada, pode causar malefícios ao indivíduo. Quando existe hemostasia ou interrupção do fluxo de sangue nas veias e artérias junto com a isquemia, pode causar danos ao nervo, lesões no músculo, lesões nas veias, alterações dos fatores de coagulação e permeabilidade do capilar (SHAW; MURRAY, 1982; VAN ROEKEL; THURSTON, 1985; TEJWANI et al., 2006). Por isso, que o entendimento adequado de sua aplicação deve ser avaliado com muita cautela.

Em relação aos efeitos negativos, o quadro 03, adaptado de Nakajima et al. (2006), cita os principais efeitos adversos que aconteceram com o uso do método até aquele momento.

No entanto, nenhuma complicação fatal foi reportada com o uso do método no estudo. Além disso, desmaios aconteceram em raros casos e hipoglicemia também foi reportada. 
Quadro 3 Efeitos adversos do método

\begin{tabular}{|cc|}
\hline Efeitos adversos & Frequência e percentual \\
\hline Hemorragia subcutânea & $1651(13,1 \%)$ \\
\hline Dormência nos membros & $164(1,297 \%)$ \\
\hline Anemia cerebral & $35(0,277 \%)$ \\
\hline Sensação de frio & $16(0,127 \%)$ \\
\hline Trombose Venosa & $7(0,055 \%)$ \\
\hline Dor & $5(0,040 \%)$ \\
\hline Coceira & $3(0,024 \%)$ \\
\hline Piora na doença cardíaca isquêmica & $2(0,016 \%)$ \\
\hline Sensação de estar doente & $2(0,016 \%)$ \\
\hline Aumento da pressão arterial & $2(0,016 \%)$ \\
\hline Embolia pulmonar & $1(0,008 \%)$ \\
\hline Rabdomiólise & $1(0,008 \%)$ \\
\hline
\end{tabular}

Quando abordado sobre os exercícios que podem ser utilizados com o método, exercícios de alongamento, caminhada, bicicleta ergométrica e treinamento resistido foram aplicados juntamente com a oclusão vascular. $\mathrm{O}$ método pode ser aplicado tanto nos membros superiores e inferiores e foi utilizado 2 a 3 vezes por semana.

Posteriormente, Yasuda et al. (2017), verificaram novamente as finalidades com que o método oclusão vascular era utilizado e possíveis efeitos adversos promovidos pelo método. Dessa vez, 232 instalações participaram do estudo. Nessa pesquisa não foram verificados efeitos adversos importantes promovidos pelo treinamento como hemorragia cerebral, infarto cerebral, trombose e rabdomiólise. No entanto, sensação de frio, dormência, hemorragia subcutânea, sonolência, dor, náusea, coceira, hipertensão, anemia e dor de cabeça foram também reportados.

Além disso, Patterson e Brandner (2018) não identificaram efeitos adversos importantes reportados por profissionais que prescrevem treinamentos com o método oclusão vascular. No entanto, dor muscular tardia, tontura, desmaio, sensação de frio e hemorragia subcutânea foram verificadas. Além disso, um estudo de caso de oclusão venosa da retina em um paciente de 45 anos após o uso do método oclusão vascular foi evidenciado (OZAWA et al., 2015). 
Com isso, considerando que a quantidade de artigos científicos publicados sobre a temática e instalações que utilizam o método aumentaram nos últimos 10 anos, a utilização adequada do método pode ser considerada segura e induzir nos pacientes efeitos benéficos, independentemente da idade, sexo e condiçóes físicas, desde que, seja considerado cada caso e anamnese rigorosa seja feita antes de sua realização.

\section{REFERÊNCIAS BIBLIOGRÁFICAS}

NAKAJIMA, T. et al. Use and safety of KAATSU training: results of a national survey. International Journal of KAATSU Training Research, v. 2, n. 1, p. 5-13, 2006.

OZAWA, Yoko et al. Vision loss by central retinal vein occlusion after Kaatsu training: a case report. Medicine, v. 94, n. 36, 2015.

PATTERSON, Stephen D.; BRANDNER, Christopher R. The role of blood flow restriction training for applied practitioners: A questionnaire-based survey. Journal of sports sciences, v. 36, n. 2, p. 123-130, 2018.

SHAW, JAMES A.; MURRAY, DAVID G. The relationship between tourniquet pressure and underlying soft-tissue pressure in the thigh. J Bone Joint Surg Am, v. 64, n. 8, p. 1148-1152, 1982.

TEJWANI, Nirmal C. et al. Tourniquet cuff pressure: the gulf between science and practice. Journal of Trauma and Acute Care Surgery, v. 61, n. 6, p. 1415-1418, 2006.

VAN ROEKEL, H. E.; THURSTON, A. J. Tourniquet pressure: the effect of limb circumference and systolic blood pressure. Journal of Hand Surgery, v. 10, n. 2, p. 142-144, 1985.

YASUDA, Tomohiro et al. Use and safety of KAATSU training: Results of a national survey in 2016. International Journal of KAATSU Training Research, v. 13, n. 1, p. 1-9, 2017. 